\title{
Time-related surface modification of denture base acrylic resin treated by atmospheric pressure cold plasma
}

\author{
Kun QIAN 1 , Hong PAN ${ }^{2,3}$, Yinglong $\mathrm{LI}^{2}$, Guomin WANG ${ }^{2}$, Jue ZHANG ${ }^{2,4}$ and Jie PAN ${ }^{1}$ \\ ${ }^{1}$ Department of General Dentistry, Peking University School and Hospital of Stomatology, Zhongguancun Nandajie 22, Beijing 100081, China \\ ${ }^{2}$ Academy for Advanced Interdisciplinary Studies, Peking University, No. 5 Yiheyuan Road, Haidian District, Beijing 100871, China \\ ${ }^{3}$ School of Stomatology, LanZhou University, 199 West Dong-gang Road, LanZhou 730000, China \\ ${ }^{4}$ College of Engineering, Peking University, No. 5 Yiheyuan Road, Haidian District, Beijing 100871, China \\ Corresponding author, Jie PAN; E-mail: panjie72@sina.com
}

\begin{abstract}
The changes of denture base acrylic resin surface properties under cold plasma and the relationships with time were investigated. Cold plasma treated the specimens for $30 \mathrm{~s}, 60 \mathrm{~s}, 90 \mathrm{~s}$, and $120 \mathrm{~s}$, respectively. Water contact angles were measured immediately after the treatment, 48 h, 15 days and 30 days later. Surface roughness was measured with 3-D laser scanning microscope. Candida albicans adherence was evaluated by CFU counting. Chemical composition was monitored by X-ray photoelectron spectroscopy analysis. Water contact angle reduced after treated for $30 \mathrm{~s}$. No changes were observed with time prolonged, except the durability. There were no differences in roughness among all groups. However, treatment groups showed significantly lower C. albicans adherence. XPS demonstrated a decrease in $\mathrm{C} / \mathrm{O}$, and this reduction was affected by treatment time. Cold plasma was an effective means of increasing hydrophilicity of acrylic resin and reducing C. albicans adherence without affecting physical properties.
\end{abstract}

Keywords: Cold plasma, Acrylic resin, Dentures, Hydrophilicity, Candida albicans

\section{INTRODUCTION}

Chronic atrophic candidiasis, also known as Candidaassociated denture stomatitis, is a very common disease affecting $15 \%$ to over $70 \%$ of the denture wearers ${ }^{1-6)}$. Candida albicans has been known as the most frequently isolated Candida species responsible for this inflammatory pathology $y^{2,4-6)}$. The adherence of C. albicans to acrylic resin denture base (polymethyl methacrylate -PMMA) has been thought to be the first step for successful colonization before subsequent plaque formation and development of pathogenesis ${ }^{7,8)}$. Surface characteristics, such as surface roughness, hydrophilicity, and surface charge have all been reported to involve in the adherence of Candida ${ }^{7-11}$. Therefore, the development of methods that could modify these denture base surface properties to prevent the adherence of $C$. albicans would be a significant advancement in the prevention of Candida-associated denture stomatitis s,9,12). $^{8}$.

Atmospheric pressure cold plasma is a complex mixture composed of ions, energetic free radicals, electrons, atoms, and molecules generated by gas discharge. It has been used in various applications, such as tooth whitening ${ }^{13,14)}$, sterilization ${ }^{15-17)}$, blood coagulation $^{18)}$, and inducing tumor cells apoptosis ${ }^{19}$. This technique has also been considered a potential method for surface modification of PMMA without inducing bulk alteration ${ }^{7,11,12,20-23)}$. Some authors have demonstrated that the plasma treatment can improve the hydrophilicity ${ }^{7,11,12,20,21,23)}$ and modify the chemical composition of the PMMA ${ }^{11,20-23)}$. However, information on the adherence of $C$. albicans to atmospheric pressure cold plasma modified denture base acrylic resin is scarce and there is no agreement until now ${ }^{7,11,12)}$. Moreover, the relationship between surface modification of denture base acrylic resins and plasma treatment time remains to be investigated.

The main purpose of the present study was to investigate the potential of different atmospheric pressure cold plasma treatment time to modify the surface physical and chemical properties of denture base acrylic resin, as well as its effect on C. albicans adherence. The durability of material modification was also evaluated. Therefore, the null hypotheses were that: (1) different cold plasma treatment time has no effect on the surface physical and chemical properties of denture base acrylic resin; (2) different cold plasma treatment time has no effect on C. albicans adherence.

\section{MATERIALS AND METHODS}

Acrylic resin specimens

The polymethyl methacrylate (PMMA) specimens $(n=104)$ were prepared with an acrylic resin denture base material (Vertex Rapid Simplified, Vertex-Dental BV, Zeist, the Netherlands) by using heat-compression mold technique. Powder and liquid acrylic resin denture base material were mixed and processed according to the manufacturer's recommendations. Specimens were made as disk-shaped, measuring $12 \mathrm{~mm}$ in diameter and $1 \mathrm{~mm}$ thickness. One side of the PMMA specimen was ground by silicon carbide paper up to grain size 1000 . Then the specimens were immersed in distilled water at $37^{\circ} \mathrm{C}$ for $48 \mathrm{~h}$ for residual monomer release and dried in air before experiments. 


\section{Cold plasma treatment}

A single electrode non-thermal atmospheric pressure plasma jet was used to treat the acrylic resin specimens. Figure 1 shows a schematic diagram of the experimental arrangement. The system consists of a Teflon tube (Daxiang, Beijing, China), a $1 \mathrm{M} \Omega$ resistor, and an outer copper foil that surrounds the Teflon tube. The outer and inner diameters of Teflon tube are $10 \mathrm{~mm}$ and $8 \mathrm{~mm}$, respectively. The outer copper foil is connected to a 10 $\mathrm{kHz}$ sinusoidal high voltage source (CTP-2000K, Suman, Nanjing, China) with an $18 \mathrm{kV}$ peak-to-peak voltage. Argon/oxygen (98\% $\mathrm{Ar}$ and $2 \% \mathrm{O}_{2}$ per volume) at a flow rate of $5 \mathrm{~L} / \mathrm{min}$ is used as working gas. The plasma is generated inside the Teflon tube near the powered outer electrode, and then propagated to generate a continuous plasma jet with a length of $5 \mathrm{~cm}$ outside the Teflon tube in the surrounding atmospheric pressure air. The distance between the tip of the plasma jet and the specimen was $10 \mathrm{~mm}$. The gas temperature near the specimen ranged from $34-38^{\circ} \mathrm{C}$.

\section{Measurements of water contact angle}

To determine the hydrophilicity of the acrylic resin specimens, contact angles of ultrapure water were measured using the sessile drop method with an automated goniometer system (OCA 15 plus, Dataphysics Instruments, Filderstadt, Germany) in combination with SCA-20 software. An image of the water droplet on the surface of the specimen was taken immediately after the contact. A single droplet $(2.0 \mu \mathrm{L})$ was assessed with two measurements (right and left contact angle) for each droplet on the specimen.

Forty five Specimens were selected to measure contact angles. They were randomly divided into five groups ( $n=9)$ : group 1 was control group (untreated); groups 2 to 5 were experimental groups (plasma treated for $30 \mathrm{~s}, 60 \mathrm{~s}, 90 \mathrm{~s}$, and $120 \mathrm{~s}$, respectively). For each group, water contact angles of specimens were measured immediately after plasma treatment and at periods of 48 h, 15 days, and 30 days with storage in deionized water at $25^{\circ} \mathrm{C}$ and air humidity of $45 \%$. These measurements were made to evaluate the treatment time-related wettability modification of acrylic resin surfaces and the durability of plasma treatment.

Evaluations of surface roughness and surface topography The surface roughness and topography were evaluated with a 3-D laser scanning microscope (LSM) (VK-X200, KEYENCE, Osaka, Japan). Nine specimens were selected. For each specimen, surface roughness and topography were measured before and after plasma treated for $30 \mathrm{~s}, 60 \mathrm{~s}, 90 \mathrm{~s}, 120 \mathrm{~s}$, respectively. Four measurements were made for each specimen to get the average surface roughness value $(\mathrm{Ra}, \mu \mathrm{m})$. The surface topography images of specimens were obtained at $\times 3,000$ magnification.

\section{Measurements of adherent C. albicans}

C. albicans strain ATCC 10231 was used. The yeasts were grown in an agar YPD culture medium (1\% yeast

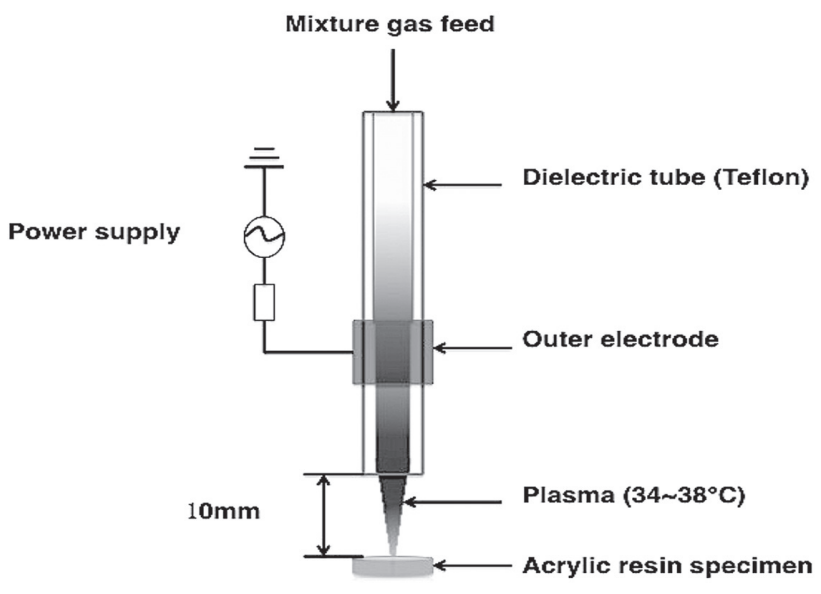

Fig. 1 Schematic diagram of the experimental arrangement.

extract, $1 \%$ peptone, $4 \%$ dextrose, and 2\% agar) for $48 \mathrm{~h}$ at $37^{\circ} \mathrm{C}$. One loopful of this young culture was transferred to $30 \mathrm{~mL}$ of YPD liquid medium (1\% yeast extract, $2 \%$ peptone, and $4 \%$ dextrose) and incubated at $37^{\circ} \mathrm{C}$ for $10 \mathrm{~h}$. The yeasts were harvested, washed twice with phosphate-buffered saline (PBS, pH=7.2) and centrifugation at $3,000 \mathrm{~g}$ for $5 \mathrm{~min}$. Candida suspension was spectrophotometrically standardized to a concentration of $1 \times 10^{7}$ cells $/ \mathrm{mL}$.

Forty five Specimens were randomly selected and divided into five groups. For each group, 9 specimens were treated as described in water contact angle measurement. The acrylic resin specimens were placed into the 24-well microtiter plates and immersed in 1.5 $\mathrm{mL}$ of the Candida suspension for $90 \mathrm{~min}$ at $37^{\circ} \mathrm{C}$ to promote adherence and colonization. Subsequently, non-adherent cells were removed from the specimens by gently washing with $2 \mathrm{~mL}$ PBS for $1 \mathrm{~min}$. The specimens were transferred to $15 \mathrm{~mL}$ centrifuge tubes and shaken for $2 \mathrm{~min}$. The amount of the C. albicans cells adhering to specimen surfaces was evaluated by colony-forming units (CFUs) analysis.

All the procedures were done by the same operator.

\section{$X$-Ray photoelectron spectroscopy}

The effect of the plasma treatment on the elemental composition and chemical bond of the acrylic resin surface was monitored by X-ray photoelectron spectroscopy (XPS) analysis (Axis Ultra, Kratos Analytical, Manchester, UK). Five specimens were selected. One specimen was untreated, other 4 specimens were plasma treated for $30 \mathrm{~s}, 60 \mathrm{~s}, 90 \mathrm{~s}$, and $120 \mathrm{~s}$, respectively. The XPS peak position was calibrated using the $\mathrm{C} 1 \mathrm{~s}$ peak at $284.8 \mathrm{eV}$ to compensate for residual charging effects. Data for percent elemental composition, elemental ratios, and peak fit analysis parameters were calculated using software supplied by Kratos with the XPS. 


\section{Statistical analysis}

Comparisons of mean contact angle, surface roughness and $C$. albicans adherence data were analyzed with One-way analysis of variance (ANOVA) in SPSS 16.0. Surface roughness was analyzed with repeated measures ANOVA. Statistically significant differences were determined at a significance level of $p<0.05$. As significant differences $(p<0.05)$ were found, the comparisons of the differences between the experimental groups were analyzed by the post hoc test of L-S-D.

\section{RESULTS}

Water contact angle

Figure 2 shows the water contact angle changes of cold plasma treated denture base acrylic resin. The water contact angle of denture base acrylic resin decreased from $77^{\circ}$ to $52^{\circ}$ after cold plasma treatment for 30 $\mathrm{s}$ (Fig. 3), which indicated that the surface became more hydrophilic after short treatment. Statistically significant differences were observed between the control and each of the plasma treatment groups $(p<0.05)$. But the experimental groups (group 2-5) did not differ from each other.

After $48 \mathrm{~h}$ of immersion in deionized water, there was significant increased in water contact angle for experimental groups $(p<0.05)$. No significant difference was observed between the control (group 1) and group $2 \quad(p>0.05)$, whereas the lower contact angles were observed in groups 3,4 and $5(p<0.05)$. After immersion in deionized water for 15 days, groups 4 and 5 exhibited lower contact angles $(p<0.05)$, whereas groups 1,2 and 3 did not differ from each other $(p>0.05)$. There were no significant differences $(p>0.05)$ in the water contact angle values between control and experimental groups after immersion in deionized water for 30 days.

\section{Surface roughness and surface topography}

Surface roughness values of all groups were presented in Table 1. There were no significant differences among all groups evaluated $(p>0.05)$. The $3-\mathrm{D}$ LSM images of the

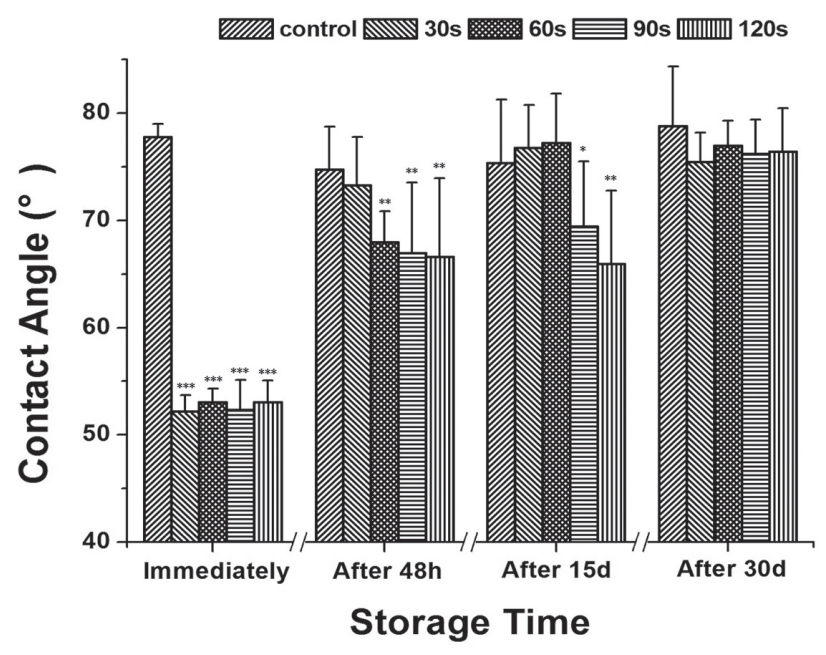

Fig. 3 Comparison of water contact angle obtained immediately after different cold plasma treatment time.

It was compared again after different periods of being stored in deionized water $(48 \mathrm{~h}, 15$ days and 30 days). ${ }^{* * *} p<0.001,{ }^{* *} p<0.01,{ }^{*} p<0.05$

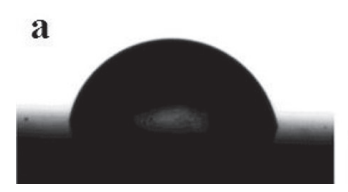

$\mathbf{b}$

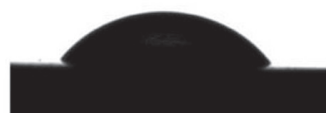

c

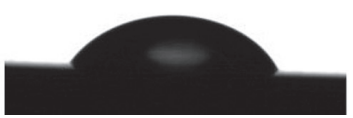

d

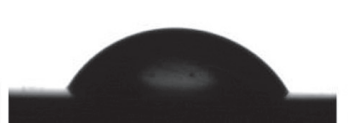

e

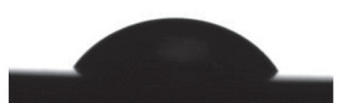

Fig. 2 Photographs of water drops for contact angle measurements on denture base acrylic resin. (a) Untreated; (b) $30 \mathrm{~s}$-treated; (c) 60 s-treated; (d) 90 s-treated; (e) 120 s-treated.

Table1 Means and standard deviations (SD) of roughness values (Ra, $\mu \mathrm{m})$ for groups

\begin{tabular}{cc}
\hline Groups & Roughness $(\mu \mathrm{m})$ \\
\hline Control & $0.22 \pm 0.01$ \\
$30 \mathrm{~s}$ & $0.23 \pm 0.02$ \\
$60 \mathrm{~s}$ & $0.23 \pm 0.01$ \\
$90 \mathrm{~s}$ & $0.21 \pm 0.03$ \\
$120 \mathrm{~s}$ & $0.22 \pm 0.02$ \\
\hline
\end{tabular}

No significant differences were found among all groups evaluated $(p>0.05)$. 

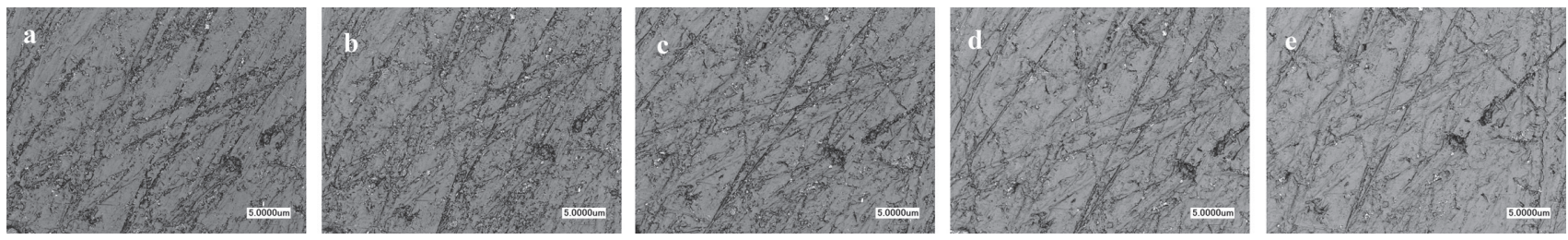

Fig. 4 3-D LSM images of specimen (a) Untreated; (b) 30 s-treated; (c) 60 s-treated; (d) 90 s-treated; (e) 120 s-treated. (original magnification $\times 3,000$, bar represents $5.0 \mu \mathrm{m}$ )

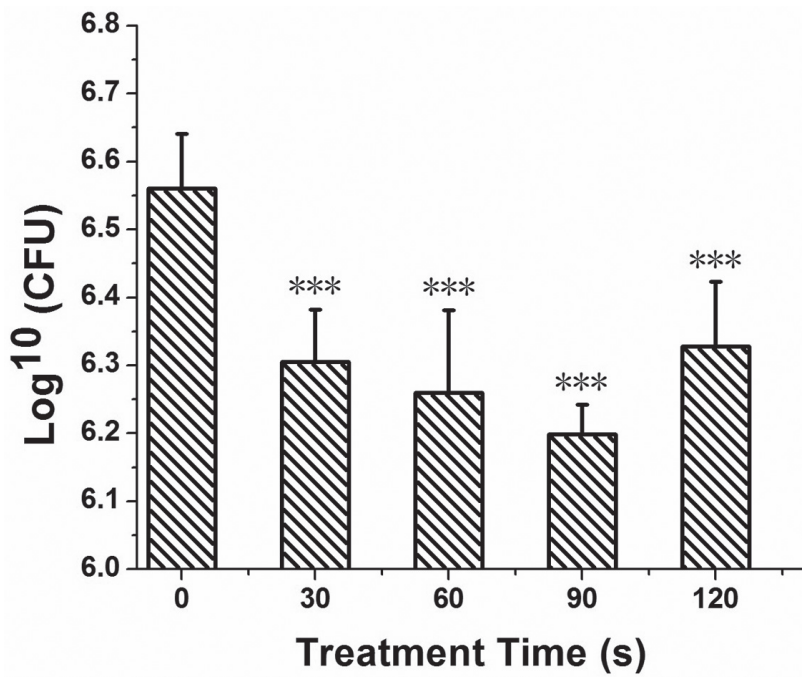

Fig. 5 The number of Candida adherence to the acrylic resin (CFU) changed with different treatment time.

Mean log numbers (CFU) and $\pm 1 \mathrm{SD}$ for all groups. $* * * p<0.001$

same specimen were obtained before and after plasma treatment (Fig. 4). The surface topography of untreated specimen showed irregular lines or cracks on the surface resulting from the polishing process (Fig. 4a). It became slightly smoother with few cracks after treatment. With the plasma treatment time increasing, the specimen surface was smoother gradually (Figs. 4b-e).

\section{C. albicans adherence}

As presented in Fig. 5, plasma treatment groups showed significantly lower $C$. albicans adherence than the control group $(p<0.05)$. When the results were analyzed with regarding to treatment time, lowest yeast cells were counted on $90 \mathrm{~s}$ group.

\section{$X$-Ray photoelectron spectroscopy}

$\mathrm{X}$-ray photoelectron spectroscopy analysis was carried out to determine the chemical modifications on specimen surfaces. The XPS wide energy spectra of control and treatment groups were presented in Fig. 6. The spectra were similar, except for the $\mathrm{C} 1$ s peak (binding energy

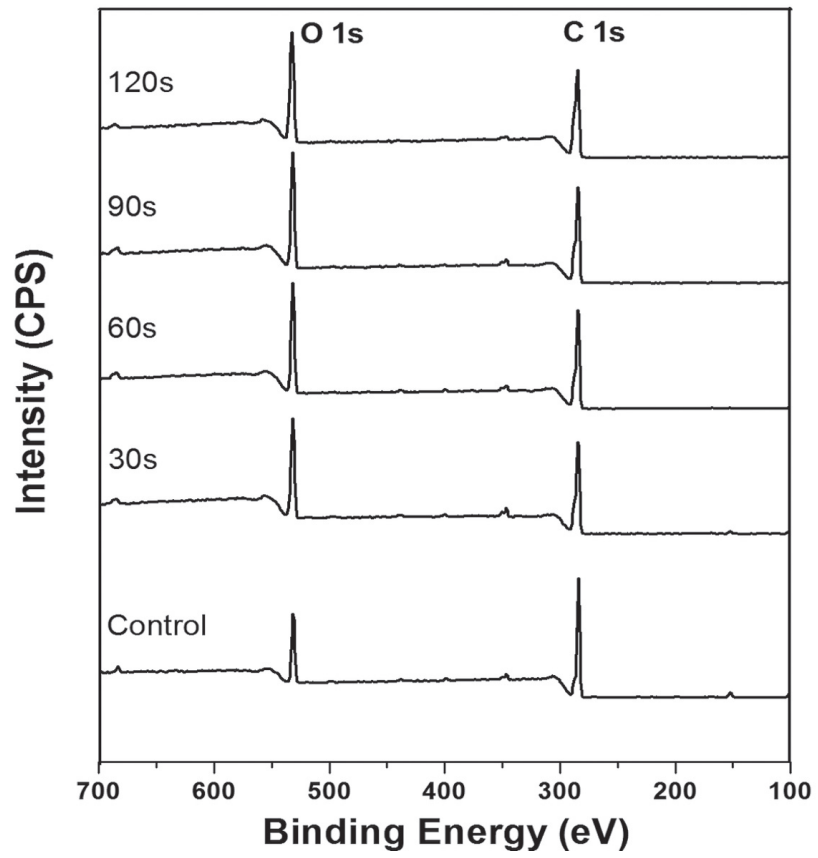

Fig. 6 XPS survey spectra of specimens with different treatment time.

around $285 \mathrm{eV}$ ) and $\mathrm{O}$ 1s peak (binding energy around $532 \mathrm{eV}$ ). The intensity of $\mathrm{C} 1 \mathrm{~s}$ peak was higher than the $\mathrm{O}$ 1s peak before plasma treatment, but it was reversal after plasma applications. As a result of the plasma treatment, the intensity and proportion of $\mathrm{C} 1 \mathrm{~s}$ peak decreased gradually whereas the percentage of $\mathrm{O} 1 \mathrm{~s}$ peak increased significantly at the same time.

As shown in Table 2, the plasma treatment reduced the ratio of $\mathrm{C} / \mathrm{O}$, and this reduction was affected by treatment time. The peak area ratio of $\mathrm{C} 1 \mathrm{~s}$ peak calculated from the XPS data were also shown in Table 2. It is obvious that plasma treatment reduced the ratio of hydrocarbon bonds (C 1s(1) peak). Increasing treatment time caused more reduction. On the other hand, the amount of methoxy group carbon (C 1s(3) peak) and carbon in the ester group (C 1s(4) peak) increased gradually. 
Table2 Relative elemental proportion and peak area ratio of C1s peak determined by X-ray Photoelectron Spectroscopy (XPS)

\begin{tabular}{|c|c|c|c|c|c|c|c|}
\hline \multirow[b]{2}{*}{ Groups } & \multicolumn{3}{|c|}{ Elemental proportion (\%) } & \multicolumn{4}{|c|}{ Peak area ratio of $\mathrm{C} 1 \mathrm{~s}$ peak (\%) } \\
\hline & $\mathrm{C}$ & $\mathrm{O}$ & $\mathrm{C} / \mathrm{O}$ & $\begin{array}{c}\text { C 1s (1) } \\
\text { Hydrocarbon }\end{array}$ & $\begin{array}{c}\mathrm{C} 1 \mathrm{~s}(2) \\
\mathrm{C} \text { atom in } \alpha \text { position }\end{array}$ & $\begin{array}{c}\mathrm{C} 1 \mathrm{~s}(3) \\
\text { Methoxy group C }\end{array}$ & $\begin{array}{c}\mathrm{C} 1 \mathrm{~s}(4) \\
\mathrm{C} \text { in the ester group }\end{array}$ \\
\hline $\mathrm{C}$ & 80.01 & 18.11 & 4.4 & 69 & 8 & 11 & 12 \\
\hline $30 \mathrm{~s}$ & 71.46 & 25.91 & 2.8 & 60 & 8 & 13 & 19 \\
\hline $60 \mathrm{~s}$ & 71.98 & 25.65 & 2.8 & 54 & 10 & 14 & 22 \\
\hline $90 \mathrm{~s}$ & 71.75 & 26.51 & 2.7 & 51 & 9 & 17 & 23 \\
\hline $120 \mathrm{~s}$ & 70.74 & 28.38 & 2.5 & 48 & 9 & 18 & 25 \\
\hline
\end{tabular}

\section{DISCUSSION}

Acrylic resin, especially polymethyl methacrylate (PMMA) is widely used materials in dentistry. In prosthodontics, acrylic resin is most commonly used for making denture base of removable partial denture and complete denture. Surface characteristics of denture base acrylic resin, such as surface roughness, hydrophilicity, surface topography, and surface charge have all been reported to involved in the adherence of Candida, which is the essential step for development of Candida-associated denture stomatitis ${ }^{7-11)}$. There has been a large body of evidence indicating that atmospheric pressure cold plasma technique may affect these surface characteristics on the surface layer without affecting their bulk properties ${ }^{7,11,12,20-23)}$.

The results of the present study revealed that cold plasma treatment of acrylic resin specimens significantly increased the surface hydrophilicity when comparing with the control group thus confirmed the findings of published investigations $\mathrm{s}^{7,11,12,21,23)}$. The water contact angle of control group $\left(77^{\circ}\right)$ was immediately reduced to $52^{\circ}$ after plasma treatment. At the same time, the XPS analysis, which demonstrated a decrease in the ratio of $\mathrm{C} / \mathrm{O}$. The spectra of the plasma treated specimen differed in the $\mathrm{C} 1 \mathrm{~s}$ region with a wider and lower peak that mean the intensities of $\mathrm{C}=\mathrm{O}$ bonds and $\mathrm{C}=\mathrm{O}-\mathrm{O}$ bonds increased. These were consistent with previous investigations, which indicated that the material became more hydrophilic due to increase in oxygen-containing functional groups on the surface of the polymer ${ }^{7,11,21)}$. Plasma treatment could result in $\mathrm{C}-\mathrm{H}$ (hydrocarbon) bonds breakage, then created free radicals onto the polymer surface. Subsequently, chemical reactions that occurred between these free radicals and oxygen from the environment incorporated polar hydrophilic groups (oxygen-containing groups) to the polymer surfaces, mainly $\mathrm{C}=\mathrm{O}^{7,11,21)}$. Similar results were appeared in our study that the proportion of the $\mathrm{C}=\mathrm{O}$ bonds (C $1 \mathrm{~s}(4)$ peak) and $\mathrm{C}=\mathrm{O}-\mathrm{O}$ bonds ( $\mathrm{C} 1 \mathrm{~s}(3)$ peak) were increased when the specimen was treated with plasma, whereas the proportion of the hydrocarbon bonds (C 1s(1) peak) was decreased relevantly.

However, there was no further hydrophilic improvement of the surface in association with increasing plasma treatment time. On the contrary, XPS analysis suggested that increasing treatment time created more polar functional groups $(\mathrm{C}=\mathrm{O}$ bonds), and caused more reduction of $\mathrm{C} / \mathrm{O}$ atomic ratio. Therefore, the null hypothesis (1) is rejected. The atmospheric pressure cold plasma treatment increased the intensity of $\mathrm{O} 1 \mathrm{~s}$ peak, which is positive correlated with the treatment time. The intensity of $\mathrm{C} 1 \mathrm{~s}$ peak was higher than the $\mathrm{O} 1 \mathrm{~s}$ peak in the untreated specimen, but it was reversal after plasma applications (Fig. 6). According to these results, a certain 'threshold' was presented in our study. It can be suspected that the improvement in the hydrophilicity of acrylic resin surface might be in association with the duration of application time before reaching this threshold. While, once the amount of polar oxygencontaining groups exceeded the threshold, prolonged treatment time couldn't cause further hydrophilic modification anymore.

To assess the durability of the plasma treatment, the water contact angle of the specimens immersed in deionized water have been followed up to 30 days after plasma treatment. According to references, Zamperini et al. ${ }^{11,12)}$ chose $48 \mathrm{~h}$ as storage period, whereas Ozden et $a l .{ }^{23)}$ chose 60 days. In our preliminary experiment, we found there were no significant differences in the water contact angle values between untreated and plasma treated specimen after immersion in deionized water for 30 days, so we chose 48 h, 15 days, and 30 days as storage periods in present study. The specimens had a tendency to recover their hydrophobicity, while prolonged of treatment time might offer a durable wettability (Fig. 3). Likewise, the XPS analysis suggested that more polar functional groups generated with the plasma treatment time increased. It could be suspected that although more polar oxygen-containing groups couldn't cause wettability improvement when above the threshold, it might influence the durability of the plasma treatment.

It has been observed that the surface roughness and topography directly influences micro-organisms initial 
adherence to surfaces, biofilm development, and Candida species colonization $^{10)}$. Some authors have demonstrated that materials with the roughest surface usually exhibit higher Candida adherence ${ }^{10,24,25)}$. On the contrary, Hahnel et al. ${ }^{26)}$ observed that there is no correlation between surface roughness and Candida adherence. Zamperini et $a l .{ }^{21)}$ reported that the 'polishing effect' of plasma treatment caused acrylic resin became much smoother with few and lower peaks. However, Yildirim et $a l .{ }^{7}{ }^{7}$ demonstrated that plasma could smoothen the cracks and lines of acrylic resin surfaces but increase the number of small hills-and-pits at the same time, which causing an increase of the roughness of the surfaces. Furthermore, Anja Liebermann et al. ${ }^{27)}$ reported that plasma treatment of PMMA had no impact on the surface roughness. Despite the controversy regarding still existed, the current results revealed that the plasma treatment smoothened the cracks and lines of specimen surface (Fig. 4), while there were no significant differences in the mean roughness values among all groups. These results indicated that atmospheric pressure cold plasma treatment might affect chemical composition of acrylic resin surface without affecting their physical properties. However, measurements of adherent $C$. albicans in this study showed that atmospheric pressure cold plasma treatment could reduce the adherence of $C$. albicans to PMMA surface. This result revealed that there was no relationship between the surface roughness and Candida adherence. The surface roughness and topography of specimens were analyzed with a 3-D laser scanning microscope (LSM) in present study. Different with profilometer, the 3-D LSM was a new kind of non-destructive profile and roughness measurement that could measure without damaging the target area, which was the common method to evaluate the surface roughness in previous investigations ${ }^{11,12,21)}$. Non-contact design made it possible for self-control experiment. Moreover, laser beam diameter $(0.4 \mu \mathrm{m})$ was significantly smaller than a roughness gauge stylus $(2 \mu \mathrm{m})$, enabling more accurate measurement.

The adherence of $C$. albicans to acrylic resin denture base has been thought to be the first step for development of Candida-associated denture stomatitis, so inhibiting the early adherence process of $C$. albicans would be important for prevention of stomatitis. According to references ${ }^{11,12,21)}$, immersion in Candida suspension for $90 \mathrm{~min}$ at $37^{\circ} \mathrm{C}$ was enough to promote early C. albicans adherence. However, there was no agreement about the adherence of $C$. albicans to plasma modified acrylic resin denture base until now. Yildirim et al. ${ }^{7}$ reported that improving the surface hydrophilicity of acrylic resin by glow-discharge plasma increased the adherence of the C. albicans. On the contrary, Zamperini et al. ${ }^{11)}$ demonstrated that plasma treatment showed promising potential for reducing the adherence of C. albicans to denture base. In current study, the results revealed that atmospheric pressure cold plasma treatment creating oxygen-containing functional groups on the surface of the modified specimens improved the surface wettability and reduced the adherence of $C$. albicans.
A linear relationship between contact angle measurements on materials and C. albicans adherence has been demonstrated in previous investigations ${ }^{8,10)}$. However, our results were different from this conclusion. Although prolonged treatment time did not cause hydrophilic improvement, the lowest adherence of C. albicans was detected on $90 \mathrm{~s}$ group. Therefore, the null hypothesis (2) is rejected. It can be suspected that the adherence of $C$. albicans on plasma-treated surface might not only relate to the hydrophilicity, but also associate with energetic species in plasma such as ions, electrons and free radicals ${ }^{20)}$. But within the limitations of this study, further investigations to confirm this hypothesis are needed. Moreover, the result in vivo situation is different from that in vitro experiment. Many other factors may affect the adherence of $C$. albicans to denture base, such as saliva, $\mathrm{pH}$ of the oral cavity, oral hygiene, and so on ${ }^{2,4,10)}$. We also want to investigate the adherence of $C$. albicans on plasma-treated acrylic resin denture base overtime. Hence, further studies are needed on this subject.

\section{CONCLUSION}

Atmospheric pressure cold plasma treatment could improve the surface wettability of denture base acrylic resin and reduced the adherence of C. albicans. Prolonged treatment time could not cause further wettability improvement, but might influence the durability of the modification. Moreover, plasma treatment could affect chemical composition of acrylic resin surface without affecting their physical properties. It supplies a promising way to prevent the Candidaassociated denture stomatitis.

\section{REFERENCES}

1) Gendreau L, Loewy ZG. Epidemiology and etiology of denture stomatitis. J Prosthodont 2011; 20: 251-260.

2) Salerno C, Pascale M, Contaldo M, Esposito V, Busciolano M, Milillo L, Guida A, Petruzzi M, Serpico R. Candida-associated denture stomatitis. Med Oral Patol Oral Cir Bucal 2011; 16: e139-143.

3) Moura JS, da Silva WJ, Pereira T, Del Bel Cury AA, Rodrigues Garcia RC. Influence of acrylic resin polymerization methods and saliva on the adherence of four Candida species. J Prosthet Dent 2006; 96: 205-211.

4) Radford DR, Challacombe SJ, Walter JD. Denture plaque and adherence of Candida albicans to denture-base materials in vivo and in vitro. Crit Rev Oral Biol Med 1999; 10: 99-116.

5) Zomorodian K, Haghighi NN, Rajaee N, Pakshir K, Tarazooie B, Vojdani M, Sedaghat F, Vosoghi M. Assessment of Candida species colonization and denture-related stomatitis in complete denture wearers. Med Mycol 2011; 49: 208-211.

6) Webb BC, Thomas CJ, Willcox MD, Harty DW, Knox KW. Candida-associated denture stomatitis. Aetiology and management: a review. Part 2. Oral diseases caused by Candida species. Aust Dent J 1998; 43: 160-166.

7) Yildirim MS, Hasanreisoglu U, Hasirci N, Sultan N. Adherence of Candida albicans to glow-discharge modified acrylic denture base polymers. J Oral Rehabil 2005; 32: 518525 .

8) Park SE, Periathamby AR, Loza JC. Effect of surface-charged poly(methyl methacrylate) on the adhesion of Candida 
albicans. J Prosthodont 2003; 12: 249-254.

9) Puri G, Berzins DW, Dhuru VB, Raj PA, Rambhia SK, Dhir G, Dentino AR. Effect of phosphate group addition on the properties of denture base resins. J Prosthet Dent 2008; 100: 302-308.

10) Pereira-Cenci T, Del Bel Cury AA, Crielaard W, Ten Cate JM. Development of Candida-associated denture stomatitis: new insights. J Appl Oral Sci 2008; 16: 86-94.

11) Zamperini CA, Machado AL, Vergani CE, Pavarina AC, Giampaolo ET, da Cruz NC. Adherence in vitro of Candida albicans to plasma treated acrylic resin. Effect of plasma parameters, surface roughness and salivary pellicle. Arch Oral Biol 2010; 55: 763-770.

12) Zamperini CA, Machado AL, Vergani CE, Pavarina AC, Rangel EC, Cruz NC. Evaluation of fungal adherence to plasma-modified polymethylmethacrylate. Mycoses 2011; 54: e344-351.

13) Pan J, Sun P, Tian Y, Zhou H, Wu H, Bai N, Liu F, Zhu W, Zhang J, Becker KH, Fang J. A novel method of tooth whitening using cold plasma microjet driven by direct current in atmospheric-pressure air. IEEE Trans Plasma Sci 2010; 38: 3143-3151.

14) Lee HW, Kim GJ, Kim JM, Park JK, Lee JK, Kim GC. Tooth bleaching with nonthermal atmospheric pressure plasma. J Endod 2009; 35: 587-591.

15) Pan J, Sun K, Liang Y, Sun P, Yang X, Wang J, Zhang J, Zhu W, Fang J, Becker KH. Cold plasma therapy of a tooth root canal infected with enterococcus faecalis biofilms in vitro. $\mathrm{J}$ Endod 2013; 39: 105-110.

16) Feng H, Sun P, Chai Y, Tong G, Zhang J, Zhu W, Fang J. The interaction of a direct-current cold atmospheric-pressure air plasma with bacteria. IEEE Trans Plasma Sci 2009; 37: 121127.

17) Lu X, Cao Y, Yang P, Xiong Q, Xiong Z, Xian Y, Pan Y. An $\mathrm{RC}$ plasma device for sterilization of root canal of teeth. IEEE Trans Plasma Sci 2009; 37: 668-673.

18) Fridman G, Peddinghaus M, Balasubramanian M, Ayan H,
Fridman A, Gutsol A, Brooks A. Blood coagulation and living tissue sterilization by floating-electrode dielectric barrier discharge in air. Plasma Chem Plasma P 2006; 26: 425-442.

19) Fridman G, Shereshevsky A, Jost MM, Brooks AD, Fridman A, Gutsol A, Vasilets V, Friedman G. Floating electrode dielectric barrier discharge plasma in air promoting apoptotic behavior in melanoma skin cancer cell lines. Plasma Chem Plasma P 2007; 27: 163-176.

20) Ozge O, Eda A A, Vasif H, Nesrin H. Surface characterization and radical decay studies of oxygen plasma-treated PMMA films. Surf. Interface Anal 2013; 45: 844-853.

21) Zamperini CA, Carneiro Hde L, Rangel EC, Cruz NC, Vergani $\mathrm{CE}$, Machado AL. In vitro adhesion of Candida glabrata to denture base acrylic resin modified by glow-discharge plasma treatment. Mycoses 2013; 56: 134-144.

22) Ben Amor S, Baud G, Jacquet M, Nanse G, Floux P, Nardin M. XPS characterisation of plasma-treated and aluminacoated PMMA. Appl Surf Sci 2000; 153; 172-183.

23) Ozden N, Akaltan F, Suzer S, Akovali G. Time-related wettability characteristic of acrylic resin surfaces treated by glow discharge. J Prosthet Dent 1999; 82: 680-684.

24) Verran J, Maryan CJ. Retention of Candida albicans on acrylic resin and silicone of different surface topography. J Prosthet Dent 1997; 77: 535-539.

25) Pereira-Cenci T, Cury AA, Cenci MS, Rodrigues-Garcia RC. In vitro Candida colonization on acrylic resins and denture liners: influence of surface free energy, roughness, saliva, and adhering bacteria. Int J Prosthodont 2007; 20: 308-310.

26) Hahnel S, Rosentritt M, Handel G, Burgers R. In vitro evaluation of artificial ageing on surface properties and early Candida albicans adhesion to prosthetic resins. J Mater Sci Mater Med 2009; 20: 249-255.

27) Liebermann A, Keul C, Bähr N, Edelhoff D, Eichberger M, Roos M, Stawarczyk B. Impact of plasma treatment of PMMA-based CAD/CAM blanks on surface properties as well as on adhesion to self-adhesive resin composite cements. Dent Mater 2013; 29: 935-944. 